\title{
Decline and demographic changes in the population of the Near Threatened brown lemur Eulemur fulvus on Mayotte
}

\author{
J. TONNABEL, I. TA T TERSALL, B. SimMEN and L. TARNAUD
}

\begin{abstract}
The population of the Near Threatened brown lemur Eulemur fulvus on the island of Mayotte was censused in 1974, 1984 and 1999. We carried out a new census in 2008, estimating individual and group densities in the three main habitat types on the island (preserved forest, anthropogenic forest and agricultural areas), and more generally evaluating population trends. Data included sex ratios and the number of young $<_{1}$ year-old per female. The census was at the end of the dry season, along 14 transect lines of 0.5 or $1 \mathrm{~km}$ length. Counts of groups and individuals were repeated three times between 07.00 and 10.00 and between 15.00 and 18.00. The densities of groups and individuals were calculated using Distance. By 2008 group and individual densities had significantly decreased in preserved forest, and there was also a decrease in group size in all habitat types. The 2008 census also showed that the overall population of E. fulvus on Mayotte has decreased by about half since 1999. We suggest that these changes reflect environmental stress associated with a decrease in available food resources. Urgent action to preserve forest habitat is necessary for the long-term survival of this lemur.
\end{abstract}

Keywords Brown lemur, Eulemur fulvus, long-term census, Mayotte, population dynamics

\section{Introduction}

ew species of lemurs live naturally outside Madagascar. However, wild-living brown lemurs Eulemur fulvus and mongoose lemurs Eulemur mongoz occur on some of the islands of the Comoro Archipelago, where they were almost certainly introduced by humans, probably within the last 1,000 years. E. fulvus occurs on the French island of Mayotte and E. mongoz on the Comorian islands of Anjouan and Mohéli. The only tangible clue to the arrival

J. Tonnabel (Corresponding author) Université Montpellier 2, Institut des Sciences de l'Evolution (UMR 5554), Place Eugène Bataillon, 34095 Montpellier cedex 05, France. E-mail jeanne.tonnabel@univ-montp2.fr

I. Tattersall Division of Anthropology, American Museum of Natural History, New York, USA

B. Simmen and L. TARNAUd Muséum National d'Histoire Naturelle-Human Sciences, Unité scientifique 104 du Muséum Eco-anthropologie et ethnobiologie, Paris, France

Received 1 March 2010. Revision requested 7 May 2010.

Accepted 7 October 2010. of E. fulvus on Mayotte is an unfortunately edentulous subfossil mandible, consistent with this identification, found at an archaeological site in the village of Dembeni. Dated to between the 9th and 13th centuries (Liszkowski, 1997), this specimen provides a minimum date of introduction. On Mayotte E. fulvus occurs today on the main island of Grande Terre, although some have recently been transferred to the islet of Mbouzy. No data are currently available for the larger offshore island of Mtsamboro.

The Mayotte brown lemur, earlier classified as an insular seventh subspecies of brown lemur E. fulvus mayottensis, is currently considered to belong to the monotypic species E. fulvus (Mittermeier et al., 2008). This species is ecologically opportunistic, inhabiting humid and dry forest types in both Madagascar and Mayotte (Tattersall, 1982; Tarnaud \& Simmen, 2002). In Madagascar it occurs in both tropical and subtropical dry forest in the west, and in tropical moist lowland and montane forest in the east. Group size in Madagascar is 3-12 (Mittermeier et al., 2008) but is typically larger on Mayotte (Tattersall, 1977; Tarnaud \& Simmen, 2002). Group home ranges in Madagascar are 7-20 ha, whereas on Mayotte they are only c. 1 ha. Sex ratios closely approach equality on both islands. As among other social and diurnal lemurs, females seem to give birth every 2 years, and only about half of the young survive their first year of life. This frugivorous-folivorous species is categorized as Near Threatened on the IUCN Red List and its populations in Madagascar are in decline (Andrainarivo et al., 2008).

Estimates of the density of E. fulvus on Mayotte were previously made in 1974 and 1984 (Tattersall, 1977, 1989), and in 1999 (Tarnaud \& Simmen, 2002). These documented similar average densities, of nine E. fulvus per ha, in 1974 and 1999. Tattersall (1989), however, reported a population crash in 1984 that he attributed to major anthropogenic disturbances that were fragmenting and destroying the forests. When Tarnaud \& Simmen (2002) found in 1999 that the population of E. fulvus had recovered, they suggested that the low population in 1984 might have been due to the effects of a severe cyclone earlier that year that destroyed feeding trees. Such events are documented to have severe effects on primate populations. Dittus (1985) reported that cyclones destroyed much of the food supply of monkeys in Sri Lanka, and Pavelka et al. (2003) observed a severe decline in the population of the howler monkey Alouatta pigra 3.5 years after a hurricane in Belize $(88 \%$ of 
the individuals disappeared). Mayotte lies in a zone of infrequent cyclones, and most of the principally secondary vegetation is poorly adapted to resist strong winds and thus recovers slowly. Moreover, a second (less powerful) cyclone occurred in 1985.

The census reported here was undertaken in 2008 to verify the current densities of E. fulvus in the three main types of vegetation on Mayotte: preserved forest, anthropogenic forest and agricultural areas. Preserved rainforests are mainly found on mountain summits; some of the anthropogenic forests surround areas of preserved forest and lie along streams as gallery forest; agricultural fields surround villages and form a mosaic with anthropogenic forest patches. After the 1999 census Mayotte was rapidly and profoundly transformed by human activities related to economic development and population growth (e.g. between 2002 and 2007 the number of inhabitants per $\mathrm{km}^{2}$ increased from 439 to 511; INSEE, 2009). Here we determine the demographic parameters of the population of E. fulvus in 2008, and compare these figures with those obtained in earlier censuses. We discuss the new estimate of the population size in historical and methodological contexts, and in particular as it relates to vegetation changes.

\section{Methods}

\section{Line transects}

JT censused the population of E. fulvus on Grande Terre, the main island of Mayotte, during the dry season and immediately before the birth season (between 1 August and 19 September 2008), specifically for comparison with the 1999 census and using similar transect-line techniques (see below for differences). In 1974 and 1984 the methods used were based on point sampling, and therefore we cannot make direct comparisons between these early censuses and that of 2008. We surveyed 14 transects of 0.5 or $1.0 \mathrm{~km}$ length (Table 1) in the three habitat types: five transects in preserved forests, four in anthropogenic forests and five in agricultural areas (Fig 1). Pascal (1997) refers to preserved forest as the most natural of the forest that lies within administrative reserves. These forests are characterized by a closed canopy with trees $>5 \mathrm{~m}$ tall. These are the forests that most closely correspond to primary formations on an island that has been profoundly transformed by human activities since the early 19th century; they are largely secondary, with remnant primary patches.

The preserved forest reserves were mapped by the French National Geographical Institute (IGN) using aerial photographs taken in 1997, and were found to cover $2.8 \%$ of Grande Terre (DAF/SEF, 1999). We used this distinction between forests within and outside reserves to compare demographic parameters between census years as it was the forest typology adopted for the earlier censuses. In more accurate mapping, Lainé et al (2010) demarcated the vegetation types of Mayotte from aerial photographs taken by IGN in 2008. For estimating the demographic parameters of E. fulvus in 2008 we used this more recent typology, which found that the estimated total surface covered by preserved forest was c. 3,075 ha ( $8 \%$ of the island) in 2008 (Lainé et al., 2010). It corresponds to the six forested areas covering the highest altitudes of Mayotte, including the forest reserves.

Anthropogenic forests include isolated patches of secondary forest types characterized by a closed canopy with trees $>5 \mathrm{~m}$ tall but that are not contiguous with preserved forests, forest patches characterized by a mixture of tree species (mainly introduced fruiting species), gallery forests and tree plantations. Lainé et al. (2010) estimated that c. 6,640 ha $(17 \%)$ of the total area of Mayotte is covered by anthropogenic forests.

Agricultural areas include all types of crops, principally subsistence, plus pastoral zones, and were estimated by Lainé et al. (2010) to cover c. 4,050 ha (10\%) of the total area of Mayotte. Mangroves, padzas (denuded areas) and urban zones were excluded from our census, although some groups of E. fulvus occur in almost all the villages and towns of the island.

\section{Sampling techniques}

Each of the 14 transects was a straight line constructed using a global positioning system (GPS) and compass, surveyed a total of three times between 07.00-10.00 and 15.00-18.0o (Table 1). These timings correspond to the diurnal peaks in lemur activity (Tattersall, 1977; Tarnaud, 2004, 2006). Observations along transect lines were made only when light and weather conditions were favourable. Following the census method described by Whitesides et al. (1988) the observers walked quietly and slowly along the transect line, stopping periodically. When a group of lemurs was detected the observer recorded the location with a GPS and measured the perpendicular distance from the survey route to the centre of the group and the perpendicular distance to the individual closest to the line, using a laser telemeter. Where trees interrupted the beam of telemeter light, successive distances were recorded. The observer then moved slowly towards the group to count the number of individuals and identify their sex and age classes (adult, young older than 1 year and young born during the year). For each group seen the observer recorded the time of the observation, the activity of each individual (resting, moving, feeding, miscellaneous) and the mean height of the group in the trees. Adequate time was taken to count individuals and identify sex and to ensure that no individuals were missed. To eliminate the risk of double counting the duration of such checking was limited to a maximum of 10 minutes. None of the transects were repeated on 2 
TABLE 1 The 14 numbered transect lines (see Fig. 1 for locations) used to survey the brown lemur Eulemur fulvus in the three habitat types in 2008 , with transect length, the total number of groups and individuals seen, the mean number of individuals per group, and the sex ratio. Each transect was surveyed three times.

\begin{tabular}{|c|c|c|c|c|c|}
\hline Site (by habitat type) & $\begin{array}{l}\text { Transect } \\
\text { length }(\mathrm{km})\end{array}$ & $\begin{array}{l}\text { Total no. } \\
\text { of groups }\end{array}$ & $\begin{array}{l}\text { Total no. of } \\
\text { individuals }\end{array}$ & Mean group size & Sex ratio \\
\hline \multicolumn{6}{|l|}{ Preserved forest } \\
\hline 1. Sohoa & 1 & 6 & 42 & 7.00 & 1.00 \\
\hline 2. Combani 1 & 1 & 8 & 49 & 6.13 & 0.96 \\
\hline 3. Convalescence 1 & 0.5 & 3 & 18 & 6.00 & \\
\hline 4. Dapani 1 & 0.5 & 3 & 19 & 6.33 & 0.84 \\
\hline 5. Bénara 1 & 0.5 & 2 & 14 & 7.00 & 0.25 \\
\hline \multicolumn{6}{|l|}{ Anthropogenic forest } \\
\hline 6. Combani 2 & 1 & 1 & 7 & 7.00 & 1.00 \\
\hline 7. Convalescence 2 & 0.5 & 1 & 6 & 6.00 & 1.00 \\
\hline 8. Dapani 2 & 0.5 & 1 & 8 & 8.00 & 1.00 \\
\hline 9. Bénara 2 & 0.5 & 3 & 25 & 8.33 & 0.88 \\
\hline \multicolumn{6}{|l|}{ Agricultural areas } \\
\hline 10. Kahani & 1 & 7 & 56 & 8.00 & 1.07 \\
\hline 11. Combani & 1 & 5 & 30 & 6.00 & 0.83 \\
\hline 12. Dzoumonyé & 1 & 2 & 19 & 9.50 & 1.17 \\
\hline 13. Bouyouni & 1 & 5 & 33 & 6.60 & 1.44 \\
\hline 14. Mronabeja & 1 & 2 & 21 & 10.10 & 0.67 \\
\hline Total/Mean $\pm S E$ & 11 & 49 & 347 & $7.08 \pm 0.77$ & $0.98 \pm 0.16$ \\
\hline
\end{tabular}

consecutive days. Care was taken to measure the distance from the line to the centre of the group to minimize the artificially inflated density estimates often reported for this method when using distance to the first individual seen (Hassel-Finnegan et al., 2008). A social group was defined for survey purposes as all individuals separated by $<20 \mathrm{~m}$.

\section{Data analysis}

Our analysis is based on the probability that detection around the transect line decreases with increasing distances from the line (Thomas et al., 2010). We used Distance v. 6.0 (Thomas et al., 2009) to fit a set of detection-probability models to the observed perpendicular distances, and selected as best the model with the smallest value of Akaike's Information Criterion. We minimized heterogeneity in detection probabilities by using the multiple covariate distance sampling engine. Marques \& Buckland (2003) reported that this engine may be used when estimating density for a subset of the data (e.g. a stratum) for which there are too few observations to fit a separate detection function to each subset. It also facilitates an increase in robustness when there are too few observations from some transects, as in the anthropogenic forest. A multiplier takes account of the repetition of the census for each transect line and we were therefore able to use the distribution of those distances to estimate the proportion of animals detected along the transect. Estimated density of groups was multiplied by an estimate of overall mean group size to obtain an estimate of individual densities.
We compared lemur densities in each habitat type using a Friedman test. For each social group we calculated the mean female fecundity as the number of juveniles observed

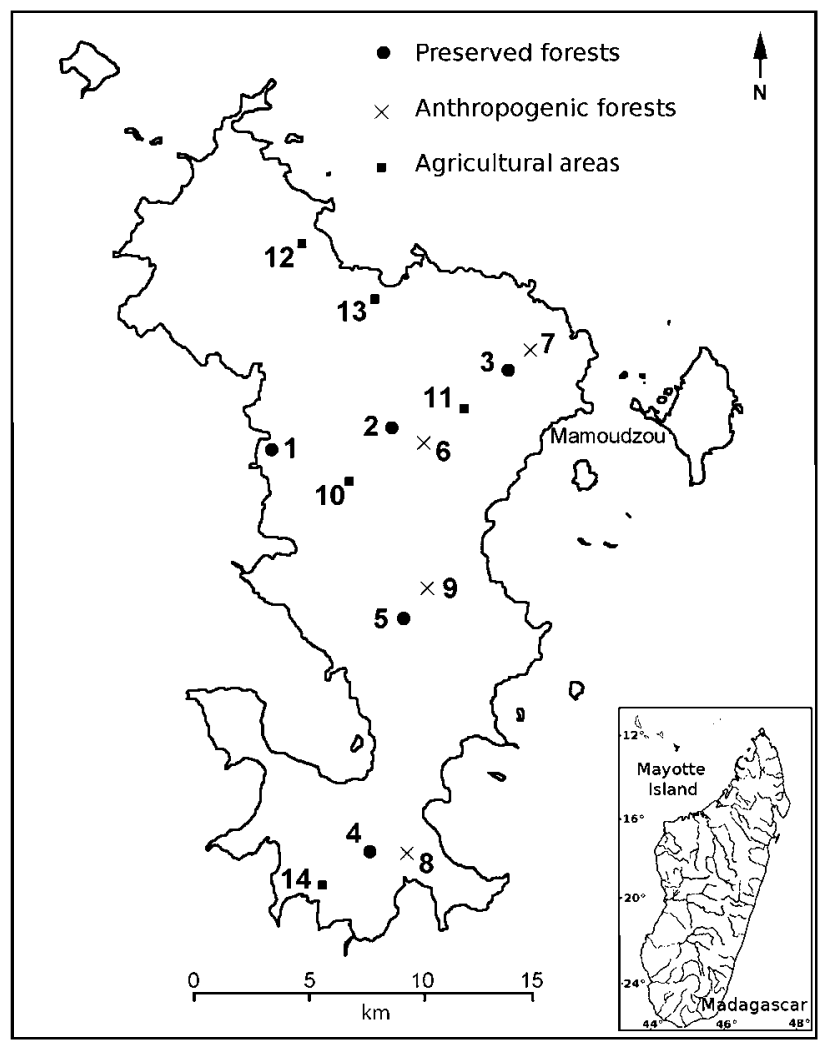

FIG. 1 Mayotte, with the locations of the 14 numbered transect lines (Table 1) used to survey the brown lemur Eulemur fulvus in 2008. 
divided by the number of adult females. The sex ratio was calculated by dividing the number of females by that of males within each social group. We compared demographic parameters (group size, group density, individual density, sex ratio, female fecundity) between the various vegetation types in 2008 using the non-parametric Kruskal-Wallis test. With the exception of the sex ratio (2-tailed $t$-test), we compared the demographic parameters for 1999 and 2008 using a 1 -sided $t$-test.

To estimate total population and any population trend between 1999 and 2008 we used the estimates of the surfaces covered by each vegetation type reported by Lainé et al. (2010). As E. fulvus requires some forest habitat with tall trees (Tattersall, 1977) we used only the area of the island covered by vegetation taller than $5 \mathrm{~m}$ in estimating the total lemur population. However, a special feature of Mayotte is the mosaic of crop fields and forest patches and therefore we included in our calculation agricultural areas containing isolated trees of $>5 \mathrm{~m}$ (Lainé et al., 2010).

We limited comparison of the 2008 data with those from 1974 and 1984 to demographic parameters such as sex ratios and group sizes. The survey methods used in 1999 and 2008 were also not identical. Although both surveys were based on line transects and group detection, in 1999 only groups and their size within a distance of $25 \mathrm{~m}$ were recorded, without reporting the distance between the transect line and the centre of each group. The distance of $25 \mathrm{~m}$ was chosen because it was the estimated limit of visibility in the forest; it is possible that, depending on the density of the trees, some groups were missed.

\section{Results}

In 2008 a total of 353 individuals of E. fulvus, in 50 groups, was recorded along a total repeated census distance of $56 \mathrm{~km}$ (Table 1). The highest and lowest densities of both groups and individuals were in the preserved forest and agricultural areas, respectively (Table 2). Within each habitat type the total number of individuals per group on each transect was homogeneous (preserved forest: $\chi \mathrm{r}^{2}=3.579, \mathrm{P}=0.466$; anthropogenic forest: $\chi \mathrm{r}^{2}=5.842$, $\mathrm{P}=0.119$; agricultural areas: $\chi \mathrm{r}^{2}=1.333, \mathrm{P}=0.856$ ). There were no significant differences between the three habitat types in either the density of groups $(H=3.343, \mathrm{P}=0.188)$ or density of individuals $(H=2.786, \mathrm{P}=0.248)$.

There was no significant difference between group sizes in the three habitats $(H=3.089, \mathrm{P}=0.213$; Table 2$)$. The mean within-group sex ratio was close to $1: 1$ (Table 1 ). There were also no significant differences in sex ratios within habitat types (preserved forest: $\chi \mathrm{r}^{2}=5.250$, $\mathrm{P}=0.154$; anthropogenic forest: $\chi \mathrm{r}^{2}=3, \mathrm{P}=0.392$; agricultural areas: $\left.\chi \mathrm{r}^{2}=4, \mathrm{P}=0.406\right)$ or between them $(H=1.171$, $\mathrm{P}=0.557)$. The mean number of young $(<1$ year old $)$ per
TAble 2 Comparisons of the 1974 (Tattersall, 1977), 1999 (Tarnaud \& Simmen, 2002) and 2008 surveys of E. fulvus on Mayotte. All means are \pm SE. A blank cell indicates the information is unavailable.

\begin{tabular}{|c|c|c|c|}
\hline & 1974 & 1999 & 2008 \\
\hline $\begin{array}{l}\text { Total transect } \\
\text { length }(\mathrm{km})\end{array}$ & & 110 & 56 \\
\hline No. of groups & 100 & 88 & 40 \\
\hline No. of individuals & 908 & 752 & 333 \\
\hline Sex ratio & 0.97 & & $0.98 \pm 0.16$ \\
\hline \multicolumn{4}{|l|}{ Group size } \\
\hline Preserved forest & & $8.59 \pm 0.69$ & $6.45 \pm 0.67$ \\
\hline $\begin{array}{l}\text { Anthropogenic } \\
\text { forest }\end{array}$ & & $8.41 \pm 0.86$ & $7.67 \pm 0.37$ \\
\hline Agricultural areas & & $9.17 \pm 0.86$ & $7.57 \pm 0.90$ \\
\hline Overall & $9.08 \pm 1.51$ & $8.7 \pm 0.2$ & $7.06 \pm 0.304$ \\
\hline \multicolumn{4}{|c|}{ Density of groups $\left(\mathrm{ha}^{-1}\right)$} \\
\hline Preserved forest & & $0.54 \pm 0.13$ & $0.45 \pm 0.08$ \\
\hline Anthropogenic forest & & $0.26 \pm 0.04$ & $0.17 \pm 0.08$ \\
\hline Agricultural areas & & $0.04 \pm 0.006$ & $0.32 \pm 0.08$ \\
\hline \multicolumn{4}{|c|}{ Density of individuals $\left(\mathrm{ha}^{-1}\right)$} \\
\hline Preserved forest & & $4.58 \pm 0.22$ & $2.88 \pm 0.55$ \\
\hline Anthropogenic forest & & $2.22 \pm 0.27$ & $1.29 \pm 0.61$ \\
\hline Agricultural areas & & $0.37 \pm 0.02$ & $2.15 \pm 0.54$ \\
\hline
\end{tabular}

female was $0.310 \pm$ SE 0.120 and this was not significantly different within habitat types (preserved forest: $\chi \mathrm{r}^{2}=4.500$, $\mathrm{P}=0.212$; anthropogenic forest: $\chi \mathrm{r}^{2}=6, \mathrm{P}=0.112$; agricultural areas: $\chi \mathrm{r}^{2}=7.529, \mathrm{P}=0.110$ ) or between them $(H=1.401, \mathrm{P}=0.496)$.

In preserved forest individual and group densities and group size decreased significantly from 1999 to 2008 (Table 2; group density: $t=2.197, \mathrm{P}=0.046$; individual density: $t=$ $2.583, \mathrm{P}=0.031$, group size: $t=-3.558, \mathrm{P}<0.001$ ). In anthropogenic forest group and individual densities also decreased significantly between 1999 and 2008 (group density: $t=$ $2.975, \mathrm{P}=0.006$; individual density: $t=4.638, \mathrm{P}<0.001$ ) but group size was not significantly different $(t=1.304, \mathrm{P}=$ o.113). In agricultural areas both group and individual densities increased significantly between 1999 and 2008 (group density: $t=-48.939, \mathrm{P}<0.001$; individual density: $t=-86.573, \mathrm{P}<0.001)$ but group size was not significantly different $(t=1.646, \mathrm{P}=0.057)$.

Pooling results for the three habitat types there was a significant decrease in group size between the 1974 and 2008 surveys $(t=4.315, \mathrm{P}<0.001)$ but no significant difference in group size between 1974 and $1999(t=1.078$, $\mathrm{P}=0.282)$. There was no significant difference in group sex ratio between 1974 and $2008(t=1.325, \mathrm{P}=0.194)$.

The estimated total number of individuals in preserved forest, anthropogenic forest and agricultural areas in 2008 was 8,849 (range 6,037-12,970), 8,552 (2,418-30,244) and $8,720(5,024-15,135)$, respectively, giving an estimated total lemur population of $26,121(16,462-41,447)$. The estimate of 
the total population in 1999, for a visibility distance of $25 \mathrm{~m}$, was 42,504 ; i.e. there appears to have been a $38.5 \%$ decrease from 1999 to 2008 . This decline was $47.9 \%$ in preserved and anthropogenic forests, whereas the estimate of the number of lemurs in agricultural areas increased by $41.5 \%$.

\section{Discussion}

The surveys of E. fulvus in 1974 and 1984 did not distinguish between habitat types, although most counts were in secondary formations, and the methodological differences between the two surveys do not allow us to make a complete comparison of demographic parameters. To assess the current extinction risk of E. fulvus on Mayotte further regular censuses need to be carried out in the same areas that we surveyed in 2008 and using the same method. However, although such work is needed to confirm the trends presented here we believe that our conclusions are sound.

The results of the 2008 survey contrast sharply with those of the earlier surveys. In preserved and secondary forests group and individual densities have decreased markedly compared to 1999 but have increased in agricultural areas that include tall trees. In all habitat types group sizes have decreased, although other demographic parameters are unchanged. The sex ratio of E. fulvus in 2008 was comparable with figures reported earlier for this species on Mayotte (Tattersall, 1977) and for red-fronted brown lemurs Eulemur fulvus rufus in Madagascar (Sussman, 1974). However, the mean size of E. fulvus groups in preserved forest declined, compared to both 1999 (Tarnaud \& Simmen, 2002) and 1974 (Tattersall, 1977). This reduced mean group size was also lower than the nine individuals per group reported for E. fulvus in Madagascar (Sussman, 1974).

The decline in group size in preserved forest appears directly related to structural changes within this habitat type: $34 \%$ of the preserved forest has been cut down in the last 10 years and has been replaced by low vegetation of $<1.5 \mathrm{~m}$ and by isolated shrubs (Lainé et al., 2010). Thus the decrease in the number of individuals per group may be a response to a decreased availability of food resources, a phenomenon that has already been demonstrated in tropical forests elsewhere (Terborgh, 1983; Chapman, 1990; Janson, 1992). Hunting on Mayotte is uncommon and cannot therefore have caused such a dramatic change in group size.

The absence of changes in demographic parameters of E. fulvus in anthropogenic forest between 1999 and 2008 is largely counterbalanced by a diminution of this type of plant cover in Mayotte (a drop of 37\%) and by a decrease in the density of individuals. As in preserved forest, the decrease in individual density in anthropogenic forest almost certainly reflects disturbances. The agricultural areas into which lemurs range are a mosaic of microhabitats where plant cover, plant diversity and the dominant plant species vary greatly, something that could introduce bias when comparing data from different studies and researchers. Nevertheless, even with these caveats, the increase in the number of $E$. fulvus in agricultural areas may be due to temporary foraging by individuals that live in nearby anthropogenic forest (especially gallery forests) but are forced into cultivated areas by food shortages in their core habitat (the lemurs were surveyed during their peaks of feeding activity). If this is the case, the low individual density in anthropogenic forest might have been due to temporary foraging absences of resident animals.

More generally, even when they contain high trees, agricultural areas probably do not provide the ecologically optimal habitat required by E. fulvus (Tattersall, 1977, Tarnaud, 2004) despite the fact that these primates are opportunists that can move long distances to feed, especially during the dry season. Such behaviour has been observed in Eulemur populations both on Mayotte (Tattersall, 1977) and in Madagascar (Overdorff, 1996). Moreover, such responses are not unique to E. fulvus: migratory behaviour related to dietary stress has also been reported for ring-tailed lemurs Lemur catta in the south of Madagascar following major environmental change after a cyclone (LaFleur \& Gould, 2009). On Mayotte the increased presence of lemurs in cultivated areas concords with increasing numbers of complaints by local people about lemurs exploiting domestic fruiting trees around villages, something that is also most readily explained by dietary stress in the lemur's usual forest habitats.

It seems evident that human impacts on the environment concomitant with economic development and human population growth are having severe consequences for E. fulvus on Mayotte. The area covered by commercial, residential and industrial development has more than doubled over the past decade, and the area with low vegetation $(<1.5 \mathrm{~m})$, mainly used for agriculture, has increased. The increase in land under agriculture explains the decrease in both preserved and secondary forest, caused by significantly increased land clearance and burning. This is occurring even in the legally protected preserved forests, and can be attributed to high human population growth, as reported by INSEE (2009).

Agricultural activity causes both forest fragmentation and habitat loss (Lainé et al., 2010), and the consequent expansion of the ratio between forest-edge zones and the forest interior may explain the decrease in lemur density within the forests of Mayotte. A similar pattern has been reported by Lehman (2006) for E. fulvus rufus in Madagascar, where edge effects negatively affect lemur densities because of the reduction in fruit abundance. Moreover, the gallery forests that used to line and protect the hydrographic network on Mayotte, and that supported a relatively 
stable population of E. fulvus (as reflected in the survey results from 1999 and earlier), now seem to have been extensively damaged (G. Viscardi, pers. comm.). The genus Eulemur is generally considered to be resilient to moderate levels of forest disturbance (Tattersall, 1982; Merenlender et al., 1998) and the brown lemurs of Mayotte have hitherto been an example of such resilience. This could, however, become ineffective if the forest becomes too fragmented. Forest modification throughout the island from 1999 to 2008 has presumably led to a substantial diminution in carrying capacity for $E$. fulvus, a process that continues. The reduced population of E. fulvus may make the species more sensitive to the effects of stochastic environmental events such as storms.

To minimize any further decline in the population of E. fulvus on Mayotte the remnant forests, which mainly occur at the highest elevations, need to be conserved. In addition, further studies to assess the extinction risk of the population are required, including more precise estimates of demographic parameters. These could be obtained by long-term focal animal sampling using capturemark-recapture protocols. Such data would facilitate the modelling of population dynamics and the examination of any density-dependency. A concurrent examination of genetic diversity, as in a recent study of the grey-headed lemur Eulemur cinereiceps in Madagascar (Brenneman et al., 2012), would facilitate a more detailed examination of extinction risk.

\section{Acknowledgements}

The research was supported financially and technically by the Association des Naturalistes de Mayotte, and the Service Environnement et Forêts of the Direction de l'Agriculture et de la Forêt. We also thank the Centre National pour l'Aménagement des Structures et des Exploitations Agricoles for providing facilities enabling us to implement GPS differential corrections, and Gérard Lainé for providing data about vegetation cover on Grande Terre. We are grateful to C. Cremades, A. Peyridieux, A. Andhume, A. Bakar Sifari, M. Mchangama and F. Flye Sainte-Marie for their invaluable help in the field, and to reviewers for their constructive criticism.

\section{References}

Andrainarivo, C., Andriaholinirina, V.N., Feistner, A., Felix, T., Ganzhorn, J., Garbutt, N. et al. (2008) Eulemur fulvus. In IUCN Red List of Threatened Species. v. 2010.4 Http:// www.iucnredlist.org [accessed 14 February 2011].

Brenneman, R.A., Johnson, S.E., Bailey, C.A., Ingraldi, C., Delmore, K.E., Wyman, T.M., et al. (2012) Population genetics and abundance of the Endangered grey-headed lemur Eulemur cinereiceps in south-east Madagascar. Oryx, 46.

Chapman, C.A. (1990) Ecological correlates of group size for three species of neotropical primates. Folia Primatologica, 55, 1-9.
DAF (Direction de l'Agriculture et de la Forêt)/SEF (Service Environnement ET ForÊT) (1999) Vegetation map of Mayotte. In La Faune Terrestre de Mayotte (ed. M. Louette), pp. 284. Annales du Muséum Royal d'Afrique Centrale (Sciences Zoologiques), Tervuren, Belgium.

DitTus, W.P.J. (1985) The influence of cyclones on the dry evergreen forest of Sri Lanka. Biotropica, 17, 1-14.

Hassel-Finnegan, H.M., Borries, C., LARney, E., Umponjan, M. \& Koenig, A. (2008) How reliable are density estimates for diurnal primates? International Journal of Primatology, 29, 1175-1187.

INSEE (Institut National de LA Statistiques et Des Etudes ECONOMIQUes) (2009) Mayotte: recensement de la population de 2007. Une population multipliée par quatre en 30 ans. Insee Première $\mathrm{N}^{\circ} 1231$, Avril 2009. Mamoudzou, Mayotte.

JANSON, C.H. (1992) Evolutionary ecology of primate social structure. In Evolutionary Ecology and Human Behavior (eds E.A. Smith \& B. Winterhalder), pp. 95-130. Aldine de Gruyter, New York, USA.

LAFleur, M. \& Gould, L. (2009) Feeding outside the forest: the importance of crop raiding and an invasive weed in the diet of gallery forest ring-tailed lemurs (Lemur catta) following a cyclone at the Beza Mahafaly special reserve, Madagascar. Folia Primatologica, 80, 233-246.

Lainé, G., Dupuy, S., Tassin, J. \& Sarrailh, J.M. (2010) Etude de la Typologie Forestière de Mayotte Final Report. Agrifor Consult - Cirad, Brussels, Belgium. pp 120.

Lehman, S.M. (2006) Spatial variations in Eulemur fulvus rufus and Lepilemur mustelinus densities in Madagascar. Folia Primatologica, 78, 46-55.

Liszkowsкi, T. (1997) Répertoire des sites archéologiques de Mayotte. SHAM, St Medard en Jalles, France.

MARques, F.C. \& BuCKLAND, S.T. (2003) Incorporating covariates into standard line transect analyses. Biometrics, 59, 924-935.

Merenlender, A.M., Kremen, C., Rakotondratsima, M. \& Weiss, A. (1998) Monitoring impacts of natural resource extraction on lemurs of the Masoala Peninsula, Madagascar. Conservation Ecology, 2, 2-5.

Mittermeier, R.A., Ganzhorn, J.U., Konstant, W.R., Glander, K., Tattersall, I., Groves, C.P. et al. (2008) Lemur diversity in Madagascar. International Journal of Primatology, 29, $1607-1656$.

OverdorfF, D.J. (1996) Ecological correlates to activity and habitat use of two prosimian primates: Eulemur rubriventer and Eulemur fulvus rufus in Madagascar. American Journal of Primatology, 40, 327-342.

PASCAL, O. (1997) La végétation naturelle à Mayotte, études quantitatives et qualitatives. Rapport DAF/SEF, Mayotte.

Pavelka, M.S.M., Brusselers, O.T., Nowak, D. \& Behie, A.M. (2003) Population reduction and social disorganization in Alouatta pigra following a hurricane. International Journal of Primatology, 24, 1037-1055.

Sussman, R.W. (1974) Ecological distinctions in sympatric species of lemur. In Prosimian Biology (eds R. Martin, D. Doyle and A.C. Walker), pp. 75-108, Duckworth, London, UK.

TARnAud, L. (2004) Ontogeny of feeding behaviour of Eulemur fulvus in the dry forest of Mayotte. International Journal of Primatology, 25, 803-824.

TARnAUd, L. (2006) Feeding behaviour of lactating brown lemur females (Eulemur fulvus) in Mayotte: influence of infant age and plant phenology. American Journal of Primatology, 68, 966-977.

Tarnaud, L. \& Simmen, B. (2002) A major increase in the population of brown lemurs on Mayotte since the decline reported in 1987. Oryx, 36, 297-300. 
Tattersall, I. (1977) Ecology and behavior of Lemur fulvus mayottensis, (Primates, lemuriformes). Anthropological Papers of the American Museum of Natural History, 52, 195-216.

Tat tersall, I. (1982) The Primates of Madagascar. Columbia University Press, New York, USA.

Tattersall, I. (1989) The Mayotte lemur: cause for alarm. Primate Conservation, 10, 26-27.

Terborgh, J. (1983) Five New World Primates. Princeton University Press, Princeton, USA.

Thomas, L., Laake, J.L., Rexstad, E., Strindberg, S., Marques, F.F.C., Buckland, S.T. et al. (2009) Distance 6.o. Release 2. Research Unit for Wildlife Population Assessment, University of St. Andrews, UK. Http://www.ruwpa.st-and.ac.uk/distance/ [accessed 21 July 2010].

Thomas, L., Buckland, S.T., Rexstad, E.A., Laake, J.L., Strindberg, S., Hedley, S.L. et al. (2010) Distance software: design and analysis of distance sampling surveys for estimating population size. Journal of Applied Ecology, 47, 5-14.

Whitesides, G.H., Oates, J.F., Green, S.M. \& Kluberdanz, R.P. (1988) Estimating primate densities from transects in a West
African rain forest: a comparison of techniques. Journal of Animal Ecology, 57, 345-367.

\section{Biographical sketches}

Jeanne Tonnabel's research interests include the conservation and population dynamics of lemurs on Mayotte Island. She is currently working on the evolution of life-history traits in fire-adapted plants in South African fynbos, and is particularly interested in linking evolutionary approaches with conservation biology. IAN T A T T E RS ALL has worked on the behaviour, ecology, biogeography, systematics and conservation of lemurs, in both Madagascar and the Comoro Islands, for 4 decades. He has studied the Mayotte Island brown lemurs since 1974. BRUNo Simmen has studied feeding ecology and sensory determinants of food choices in primates for more than 15 years, with a particular interest in understanding how the study of primates can inform our understanding of the biological and evolutionary basis of human feeding behaviour. LAURENT TARNAUD studies feeding ontogeny and nutritional determinants of food choices of primates, using a comparative approach with various species in Madagascar, Mayotte and Japan. He has worked on demographic variation of Mayotte Island brown lemurs since 1999. 